\title{
Combating Acid Rain: Physically Based Process and Product Yadav RC*
}

School of Civil and Water Resources Engineering, Bahir Dar University, Ethiopia, Central East Africa

\begin{abstract}
The acid rain caused due to air pollution from the presence of $\mathrm{CO}_{2} \mathrm{SO}_{2}$ and $\mathrm{NO}_{2}$, has long been experienced world wide, albeit with variation of intensity of occurrences in different regions and time of a year. In this study a product and process was developed to eradicate insitu the $\mathrm{CO}_{2}$ and $\mathrm{SO}_{2}$. The product and Process designated as Geoact-Ca5 was adequately tested for the pollutants that exist in stratified columnar situation similar to that in open environment. Action of the Geoact-Ca5 converts the polluting agents responsible for causing acid rains and its harmful effects in to inert and harmless product or even to some useful products such as $\mathrm{CaCO}_{3}$ and $\mathrm{CaSO}_{4}$. The product and process is applicable for eradication of acid rain causing pollutants such as $\mathrm{CO}_{2}$ and $\mathrm{SO}_{2}$ in any region and before the occurrence of events of rain or snow and situation that leads to the dry deposits of acid rain. Thus, unmaneuverable problem of acid rain can be controlled by applying the Geoact-Ca5 at selected locations and time of the year. The budget for the application of Geoact-Ca5 can be derived by selling the carbon credits generated by accounting the eradication. New areas of research are suggested.
\end{abstract}

Keywords: Acid rain; Air pollution; Carbon trading; Global warming; $\mathrm{CO}_{2} ; \mathrm{SO}_{2} ; \mathrm{NO}_{2}$

\section{Introduction}

When fossil fuels such as coal, gasoline and fuel oils are burned, they emit oxides of sulphur, carbon and nitrogen in to the air. These oxides combine with the moisture in the air to form sulphuric acid, carbonic acid and nitric acid, respectively. When it rains or snow, these acids are brought to the earth in what is called acid rain. The acid deposits are of wet when acids occur by any form of precipitation and dry type when deposits occur via dry deposition in the absence of precipitation and in the dry deposits particle and gases stick to the ground, plants and other surfaces. The dry deposits can be responsible for $20-60 \%$ of total acid deposition [1].

Scientist use $\mathrm{pH}$ factor to measure acidity or alkalinity of liquid solutions. On scale from 0 to 14 , the number 0 represents the highest level of acidity and 14 represents most basic or alkaline. Distilled water contains neither acids nor alkaline or bases is designated 7 or neutral. If the $\mathrm{pH}$ level of rain falls below 5.5, the rain is considered acidic. The rainfall in central United States and Western Europe often range from 4.5 to 4 [2].

\section{Damages from the acid rain}

The effect of acid rain can be devastating to many forms of life including human life. Its effects can be most vividly seen, however, in lakes, rivers and streams and on vegetations. Acidity in water kills almost all life forms. By the early 1990s ten thousands of lakes were destroyed by acid rain. The problem has been very severe in Norway, Sweden and Canada. The United States Environmental Protection agency (EPA) website states that of the lakes and streams surveyed acid rain caused acidity in $75 \%$ of acid lakes and about $50 \%$ of the acid streams [1].

During the course of the $20^{\text {th }}$ Century, acidity of air and acid rain has come to be realized as a leading threat to the stability and quality of the Earths' environment. Most of this acidity is produced in the industrialized nations of the northern hemisphere, the United States, Canada, Japan and most of the countries in the Eastern and Western Europe [1]. Science Daily [3] criticized the EPA and Bush administrations plans that made it easy with new important wrinkle story, for power plants, mills, refineries, and chemical factories (major sources of acid rain nation wise) to expand without installing new pollution control and the senate consideration of clean prospect.

The threat posed by the acid rain is not limited by geographic boundaries, for prevailing winds carry pollutants around the globe. For example much researches support the conclusion that pollution from coal powered electric generators is the ultimate cause of severe acid rain problem in eastern Canada and North Eastern United States. The destructive effects of acid are not limited to the natural environments. Structures made of stones; metal and cement have also been damaged or destroyed. Some of the worlds' great monuments including Cathedral of Europe and the Collosium in Rome have shown sign of deterioration caused by acid rain [1].

Although the cost of anti pollution equipments such as burners, filters, chemicals and washing devices is great, the cost of damage to environment and human life is estimated to be much greater because the damages may be irreversible. Mathew [4] reported that although preventive measures are being taken up, 500,000 lakes in North America and more than 118 million cubic meters of timbers in Europe could be destroyed before the end of $20^{\text {th }}$ century.

\section{Beneficial effect of acid rain: a contrary view}

Sulfate in acid rain is known to suppress methane $\left(\mathrm{CH}_{4}\right)$ emissions from natural freshwater wetlands. Gauci et al. [5] found that acid rain rates of $\mathrm{SO}_{4}^{2-}$ deposition may help reduce $\mathrm{CH}_{4}$ emissions from paddy fields. Emissions from rice plants treated with simulated acid rain at levels of $\mathrm{SO}_{4}^{2-}$ consistent with the range of deposition in Asia were reduced by $24 \%$ during the grain filling and ripening stage of the rice

*Corresponding author: Yadav RC, School of Civil and Water resources Engineering, Bahirdar, Ethiopia, Central East Africa, E-mail: ramcyadav@rediffmail.com

Received November 01, 2012; Accepted December 19, 2012; Published December 21, 2012

Citation: Yadav RC (2013) Combating Acid Rain: Physically Based Process and Product. Hydrol Current Res 3: 144. doi:10.4172/2157-7587.1000144

Copyright: (c) 2013 Yadav RC. This is an open-access article distributed under the terms of the Creative Commons Attribution License, which permits unrestricted use, distribution, and reproduction in any medium, provided the original author and source are credited. 
season which accounts for $50 \%$ of the overall $\mathrm{CH}_{4}$ that is normally emitted in a rice season. A single application of $\mathrm{SO}_{4}^{2-}$ at a comparable level reduced $\mathrm{CH}_{4}$-emission by $43 \%$. The first mechanism is that the low rates of $\mathrm{SO}_{4}^{2-}$ may be sufficient to boost yields of rice and, in so doing, may cause a reduction in root exudates to the rhizosphere, a key substrate source for methanogenesis. Decreasing a major substrate source for methanogens is also likely to intensify competition with sulfate-reducing microorganisms for which prior $\mathrm{SO}_{4}^{2-}$ limitation had been lifted by the simulated acid rain $\mathrm{S}$ deposition.

Study by Wang et al. [6] on effect of simulated acid rain on control of termites revealed that acid rain with $\mathrm{pH}$ 2.5-3.0 was more effective than its other treatments.

\section{Mechanism of damage by acid rains}

The Science daily [3] highlighted results of study published in the ecosystem and health revealed that acid rain damage to America's forest may be much more wide spread than previously believed. It was quoted to actually create condition in trees similar to compromised immune system in human establishing vulnerability with great potential implications. As with Immune compromised humans, plants may appear and function as if they were healthy until exposed to even a routine stress or disease, then experience decline for more exaggerated than expected. The acid rain depletes calcium and weakens high elevation red spruce making them vulnerable and as pointer of freezing injury. Calcium is a critical ingredient in plant stress response system. Acid rain depletes plant cellular calcium that suppresses the capacity of trees to survive environmental stresses. In another study this author [7] developed and patented a process for eradication of polluting gas in the year 2010.

While the problem of acid rain is of global concern, there had been situation of helplessness and problems of acid rain is going on at its pace. Some preventive measures such as technical international treaties and carbon trading were launched and brought in action in some part of the world. No place can be taken as acid rain free due to limitless movement of pollutants beyond geographical boundaries. If there can be a method to eradicate the acid rain forming agents at place and time of their occurrence, the problem of acid rains can be ameliorated to a great extent. The objective of this study was to find ways and means to eradicate the polluting agents responsible for causing acid rains and convert the harmful effects that occur in to harmless or even to convert the acid rain causing pollutants to some useful products. In the present study, a manifestation was devised in a simple, feasible, replicable and affordable measure for combating the acid rain by eradicating the acid rain forming polluting agents to combat the acid rain problems.

\section{Materials and Methods}

\section{Chemical reactions}

The chemical reactions those cause acid rains are described in detail in $[1,8]$. Carbon dioxide and water in the air react together with to form carbonic acid, a weak acid. The carbonic acid then can ionize in water forming low concentrations of hydronium ions. The $\mathrm{CO}_{2}$ is produced by oxidization of carbon in the soil in presence of aeration ie aerobic decomposition [9]. In absence of aeration i.e., occurrence of anaerobic reaction carbon is utilized for production of methane gas $\mathrm{CH}_{4}$ which later is converted in to $\mathrm{CO}_{2}$ again. The $\mathrm{CO}_{2}$ is also produced by the respiration process by the living animal and plants. Plants and tree vegetation utilize the $\mathrm{CO}_{2}$ in presence of Sun light to perform photo synthesis to produce carbohydrate and release oxygen. During the cloudy days the photosynthetic activity is not performed in absence of light but respiration continues to occur. The atmosphere gets flooded with excessive $\mathrm{CO}_{2}$ that causes heavy air pollution. However, this excessive flooding of $\mathrm{CO}_{2}$ is not getting cognizance of environmentalists who always think that vegetation work as sink for $\mathrm{CO}_{2}$ assimilation.

The sulphur dioxide generated by burning of fossil fuels in various furnaces and power plants gets oxidized by reaction with the hydroxyl radical by inter molecular reaction and gets converted in the sulphur trioxide $\left(\mathrm{SO}_{3}\right)$. In the presence of water the $\mathrm{SO}_{3}$ is quickly converted in to sulphuric acid $\left(\mathrm{H}_{2} \mathrm{SO}_{4}\right)$.

When clouds are present, the loss rate of $\mathrm{SO}_{2}$ is faster than that can be explained by the gas phase chemistry alone [1]. This is due to reaction in the liquid water droplets. Sulphur dioxide dissolves in water and then like carbon dioxide hydrolyses in a series of equilibrium reactions. There are large numbers of aqueous reactions that oxidize sulphur in various forms leading to formation of sulphuric acid. Sulphur leaches down to join the ground water. The well water under specific circumstances forms $\mathrm{H}_{2} \mathrm{~S}$ that causes fatality in the well [10]. However, in recent years, as described in introductory part of this study, researches support some good effect of $\mathrm{SO}_{4}$ deposition caused by acid rains.

The nitrogen dioxides emitted by the vehicles form the nitric acid in reaction with the $\mathrm{OH}$, the hydroxyl radicals. Diesel vehicles contribute nitrogen oxide $\mathrm{NO}_{\mathrm{x}}$ in enormous quantity, nearly 95\% [11]. Several reports exist [12] on emission of $\mathrm{NO}_{2}$ from the soil under wheat fertilized with nitrogenous fertilizers.

\section{Experimental details}

This research was carried out in a well located close to the forest in deep gullies at Chhalesar, District Agra, Uttar Pradesh, India (7802’ E, $27^{\circ} 10^{\prime} \mathrm{N}$ and $169 \mathrm{~m}$ above mean sea level). The well was equipped with centrifugal pump installation. The method was devised to eradicate toxic gas present in the well in Sept 1999. The poisonous killer gas was identified as $\mathrm{CO}_{2}$ by testing it by lighting lantern method.

For continuous flaming it essentially requires continuous supply of oxygen. The flames get extinguished in absence of oxygen and presence of carbon dioxide. The level of gas in the well was ascertained by hanging lighting lantern. The lighting lantern got extinguished conforming the presence of $\mathrm{CO}_{2}$. After ascertaining the level of presence of $\mathrm{CO}_{2}$ eradication of gas was carried out by preparing and application of Geoact-Ca5. After first round of chemigation treatment, level of presence of poisonous gas in the well was again ascertained by hanging lighting lantern. The Geoact-Ca5 was again applied to completely eradicate the remaining $\mathrm{CO}_{2}$. Presence of lantern flame lighting indicated complete eradication of $\mathrm{CO}_{2}$. As an extra precaution, another round of the Geoact-Ca5 application was performed to eradicate $\mathrm{CO}_{2}$ emitted by the flaming lantern used for testing of presence of gas during the experimentation. Next day the pump repairing work was completed and irrigation started.

\section{Results}

The experiment represented actual situation of occurrence of pollutions that cause acid rain in the atmosphere. There was no study of occurrence of acid rain at the site of experiment, instead, it was a study to eradicate the acid rain causing pollutants and eliminate possibility of occurrence of acid rain. It was an effort to attack the root cause of acid rain forming agents such as $\mathrm{CO}_{2}$ and $\mathrm{SO}_{2}$ and total eradication of acid rain formation at the site of application.

Flaming lantern when lowered in he well got extinguished that confirmed presence of toxic and suffocating killer gas in the well. The 
lantern flamed only up to some depth in the well; it indicated type and level of existence of gas. Extinguishment of gas confirmed that it was $\mathrm{CO}_{2}$. Table 1 contains details of well and various operations. Gas was almost full in the well as indicated by the flaming lantern and another strong flaming object lowered in the well. Rate of eradication of the gas was about $7 \mathrm{~m} /$ round of Geoact-Ca5 performed. It completely eradicated the $\mathrm{CO}_{2}$ at the experimental site. The lantern kept flaming in the well that confirmed complete eradication of the $\mathrm{CO}_{2}$ in the well. The cost of material used for eradication was just Rs 5/event of complete eradication.

The first round of operation reduced level of $\mathrm{CO}_{2}$ to almost half of the level it was present in the well. Second round completely eradicated $\mathrm{CO}_{2}$ in the well. The $\mathrm{CO}_{2}$ present in the well got converted in to $\mathrm{CaCO}_{3}$. When the $\mathrm{CO}_{2}$ got eradicated suffocation of persons when entered in the well did not occur again. The maintenance work force was able to carry out repairing work as usual. Thus, pumping set could be brought in operation after the rainy season.

Reoccurrence of the existence of particular gas was again noticed on $23^{\text {rd }}$ August 2001 in the same well. People who entered in the well got suffocated. The basic material was again procured from the market. Entire operation again was conducted in presence of scientists, technical officers and workers at the farm to prove the functioning of the process so developed, beyond doubt and full satisfaction of different strata of the society. Thus, Geoact-Ca5 works very well to eradicate the gas $\mathrm{CO}_{2}$, which is almost $50 \%$ responsible for causing green house effect of global warming. The $\mathrm{CaCO}_{3}$ is utilized in neutralization of acid that has fallen on the ground or it moves in the soil. The water resource i.e., the well equipped with the centrifugal pump with belt pulley failed due to deep depression of groundwater table. Hence the site has been equipped with deep tube well fitted with turbine pump. Since it got abandoned the opportunity of taking more observations at site got exhausted.

Although the Geoact-Ca5 has been experimentally demonstrated to convert $\mathrm{CO}_{2}$ in $\mathrm{CaCO}_{3}$, it is equally applicable for eradication of $\mathrm{SO}_{2}$ leading to $\mathrm{SO}_{3}$ by converting it in $\mathrm{CaSO}_{4}$. The $\mathrm{CaSO}_{4}$ works as an amendment in the acid soil. Thus, air pollutant which causes acid rain is converted in to a useful product by application of Geoact-Ca5. Thus, it was established that application of Geoact $\mathrm{Ca}-5$ works well to eradicate acid rain forming polluting agents and combat problem of acid rain at the selected sites.

\section{Discussion}

From the chemical reactions involved in the process of air pollution it is clear that the $\mathrm{CO}_{2}$ and $\mathrm{SO}_{2}$ can be eradicated by the product and process Geoact-Ca5 developed in this study. The website [1] reports that $70 \mathrm{Tg}(\mathrm{S})$ per year in the form of $\mathrm{SO}_{2}$ comes from fossil fuel, combustion

\begin{tabular}{|l|l|c|c|}
\hline S.No & Particulars & Units & Quantity \\
\hline 1 & Diameter of well & $\mathrm{m}$ & 2 \\
\hline 2 & Depth of well & $\mathrm{m}$ & 20 \\
\hline 3 & Level of flaming lantern & $\mathrm{m}$ & 5 \\
\hline 4 & Level of strong flame extinguished & $\mathrm{m}$ & 8 \\
\hline 5 & Level of gas from the top & $\mathrm{m}$ & 5 \\
\hline 6 & Level of gas after first round of application of Geoact-Ca5 & $\mathrm{m}$ & 16 \\
\hline 7 & Level of gas after second round of Geoact-Ca5 application & $\mathrm{m}$ & 20 \\
\hline 8 & Gas eradication rate per round & $\mathrm{m}$ & 7.5 \\
\hline 9 & $\begin{array}{l}\text { Cost of } \mathrm{CO}_{2} \text { gas eradication per instance of gas } \\
\text { presence in well }\end{array}$ & $\mathrm{Rs}$ & 5 \\
\hline
\end{tabular}

1US \$=INR 48/(Approximate)

Table 1: Details of particulars of well and eradication operation. and industry, $2.8 \mathrm{Tg}(\mathrm{S})$ from wild fires and $7-8 \mathrm{Tg}(\mathrm{S})$ per year from volcanoes. While some efforts have been made to reduce emission of $\mathrm{SO}_{2}$ from combustion of fossil fuels and development of green coal for use in the generation plants, the contribution toSO $\mathrm{S}_{2}$ emission by the wild fires and the volcanoes do pose the problem. There were some ways to reduce the $\mathrm{SO}_{2}$ released by the fossil fuel and combustions viz. wet scrubbing and other developments, but no method to reduce the risks of $\mathrm{SO}_{2}$ emissions from natural/accidental causes, where the polluting gas can not be brought to the controlled reaction chambers. The development of product and process Geoact-Ca5 enables eradication of polluting gases once it has escaped to atmosphere, on as and where is basis.

The acid rain comprises dry and wet acid deposit. The polluting agent in air can be eradicated by application of Geoact-Ca5 under any condition and environment can be made free from the acid rain causing pollutants. The resultants after eradication i.e., $\mathrm{CaCO}_{3}$ and $\mathrm{CaSO}_{4}$ become useful substance that can neutralize the acidity of water and soil or as and when acid rain occurs due to presence of pollutants otherwise or afterwards.

The regions infested with the problems of acid rain are identified and known [1]. These areas are most of Europe (particularly Scandinavia), many parts of United States (particularly, New York), South Western Canada, South Eastern Coast of China and Tiwan. Other potential areas namely, much of South Asia (Indonesia, Malaysia and Thiland), Western South Africa, Southern India, Srilanka and West Africa (Ghana, Togo and Nigeria) could all be prone to acid rain in future. The product and process developed in this study viz. Geoact-Ca5, could be used to eradicate the problem causing pollutants at the site which otherwise can not be possible to overcome the acid rain problem. The areas falling in the down ward wind direction from the emitting sources can be treated first to reduce the likely danger of acid rain. Further, the forest cover at the high altitude, often surrounded by clouds and fogs i.e. high concentration of gaseous precursors of acid rain can be treated by the product and process developed in this study. The visibility is also reported [1] to be reduced by the presence of sulphate and nitrate aerosols and particles in atmosphere. These indications guide as to which area should be treated for effective and maneuverable exercise in containing the problem of acid rain.

The cost of materials used is very low, it does not involve electrical energy for product processing and application, and it facilitates its large scale application. The cost and organization of activity for coverage of area will be proportional to the size of area. For site specific small area eradication the cost of material and application is very little. Since the problem of acid rain is a global, efforts on eradication when taken on global basis would be very effective.

Indirect approach for curbing the pollution by carbon trading has been just a cosmetic approach, where the net benefits are yet to be realized. The complete eradication by the new product and process would be sure shot in this direction. The finances so derived from the carbon trading can fulfill major proportion of the budget demand for the exercise for reduction of acid rain. This strategy needs reconsideration at the intergovernmental panel level. Joint collaborative venture would save forest vegetation, properties and monuments and expenditures incurred on maintaining public health [1].

Scientific reports indicate that lakes are strong contributors of $\mathrm{CO}_{2}$ in the atmosphere [13]. The lakes can be treated by aerial sprays to convert $\mathrm{CO}_{2}$ and $\mathrm{SO}_{2}-\mathrm{SO}_{3}$ in at suitable intervals to form $\mathrm{CaCO}_{3}$ and $\mathrm{CaSO}_{4}$, which will improve the quality of water worsened by the acid 
rain that has already occurred or that may occur intermittently in the intervening period of eradication exercises. Further, set-up has been developed to entrap and eradicate [14] the $\mathrm{CO}_{2}$ in the lakes to control the contribution of $\mathrm{CO}_{2}$ by the lakes to atmosphere. That means that the pollutions emitted directly or indirectly by the large water bodies, blamed to be contributor, can be eliminated from the environment pollutions.

Methane and nitrous oxides are long lived natural trace gases that account for nearly $20 \%$ anticipated atmospheric global warming. Mosier et al. [15], reported the methane uptake and $\mathrm{N}_{2} \mathrm{O}$ emission in fertilized wheat, native grass and its fertilizer applied condition. The study revealed that nitrogenous fertilizer decrease uptake of methane and increase $\mathrm{N}_{2} \mathrm{O}$ flux to the atmosphere. Desert soils are significant contributors to global $\mathrm{CH}_{4}$ soil sink term [16]. Study also suggested that the magnitude of $\mathrm{CH}_{4}$ consumption by the desert soil could increase substantially if there is net increase in arid region moisture. The contribution of methane is not considered to cause the acid rain. There was no feasible method to tackle the problem of nitrous oxide responsible for global warming, except to make mandatory control on reduction of emission from the vehicles. Green fuel (biodiesel) and use of hydroxyl to alter emission characteristics and use of portable devices to collect and dispose off the pollutants were invented, but all these methods work at the point source and not for the non-point source. Recently, Yadav et al. [17] devised novel method of Cynobacteria leguminous crops intra row banding for promoting nitrogen fixation and its use by the cereals and oilseed crops. For large scale applications of the intra row banding a high-tech seed drill was developed at the Research Center, Agra, Uttar Pradesh, India.

Limitation of sink theory to operate during rainy, cloudy and Sunshine freed days causing $\mathrm{CO}_{2}$ flooding, not yet visualized by other conservationists, can be overcome by entrap and eradicate method [14].

The artificial method eradicating methane emission from acid rain formation [5] is parallel to give poison to someone to eradicate another poison. In the artificial acid rain formation the boundary cannot be fixed due to reasons described in the introduction part of the manuscript. It will always have some side effect in the atmosphere. The new method presented in the present study is a real control method to combat acid rain without any side effect. May be on larger paddy fields this method may not be operated to eradicate acid rain and if applied it will convert the $\mathrm{SO}_{2}-\mathrm{SO}_{3}$ in to calcium sulphate the same desirable product as achieved in artificial acid rain. Further, in a different study the author [18] devised a paddy culture for zero methane emission and enhancing productivity of paddy fields. Thus, there is still better novel simple method to eradicate methane contribution from the paddy fields. There are other simple treatments to enhance sulphate in the soil by method presented by [2]. The year round cropping system can take care of methane emission from the paddy fields post harvest as described in the paddy culture.

Recently, Yadav et al. [17] demonstrated utility of intra row bending of Cynobacteria leguminous crops for harnessing $\mathrm{NO}_{2}$ for nitrogen fixation in nitrogen fertilizer applied wheat crop that will reduce, to some extent, the $\mathrm{NO}_{\mathrm{x}}$ pollution to atmosphere and acid rain due to formation of Nitric acid.

\section{Conclusion}

The global problem of acid rain can be ameliorated by launching new venture of application of product and process developed (Geoact$\mathrm{Ca5}$ ) in the present study. The selected problem intensive areas can be eradicated of acid rain, with convenience, feasibility and economy, at off sites as it exist on as is where is basis in the atmosphere. Further research areas are chalked out:

- Monitor the acid rain in the area so as to know the place where acid rain problem is severe.

- Conduct application of the Geoact $\mathrm{Ca}-5$ in some valleys or areas where incidences of acid rains are severe due to $\mathrm{CO}_{2}$ and $\mathrm{SO}_{2}$

- Apply the Geoact $\mathrm{Ca}-5$ at cloudy sites during initial rains and monitor the degree of eradication of acid rain which may occur during following rain showers.

- Carryout study on acid rain formation and/or reduction with Cynobacteria leguminous crops inter cropping and intra row banding.

- Assess the eradication of $\mathrm{CO}_{2}$ and $\mathrm{SO}_{2}$ to quantify carbon credit for carbon trading

\section{References}

1. Acid rain, From Wikipedia, the free encyclopedia.

2. Yadav RC (2012) Innovative application of scientific facts for nutrient recovery from waste water streams for sustainable agriculture and protection of environment. Hydrology: Current Research published online 3: 1-11.

3. Science Daily (2002) Damage from acid rain pollution is far worse than previously believed.

4. Mathew KM (1996) Manorma year Book. Malyalam Manorma 70-71.

5. Gauci V, Dise NB, Howell G, Jenkins ME (2008) Suppression of rice methane emission by sulfate deposition in simulated acid rain. J Geophys Res 113, G00A07.

6. Wang JJ, Zhang JP, He L, Zhao ZM (2006) Influence of long term exposures to simulated acid rainson development, reproduction and acaricide susceptibility of caramine spiola mite, Tetranychuf cinnabarinus. J of Insect Science 6: 15362442.

7. Yadav RC (2010) A process for eradication of polluting gas. Patented, India, patent office New Delhi.

8. Seinfeld JH, Pandis SN (1998) Atmospheric Chemistry and Physics: From Ai Pollution to Climate Change, John wiley and Sons Inc ISBN 0-471-17816-0.

9. Hashimoto S, Masakazu S (2002) Vertical distributions of carbon dioxide diffusion coefficients and production rates in forest soils. Soil Sci Soc Amer J 60: 1151-1158

10. Yadav RC, Dube SK, Paritosh S (2008) Fatality in water well-the main source of water supply in the Braj Kshetra of North India. National seminar on House Hold Water Technology ( HHWT 2008), HCST, Mathura, India.

11. Qasim SZ (2000) Hydrocarbon sector and its impact on human health and environment. Bionotes 2: 45-47.

12. Majumdar, Deepanjan, Pathak, Himanshu, Kumar, et al. (2002) Nitrous oxide emission from a sandy loam inceptisol under irrigated wheat in India as influenced by different nitrification inhibitors. Agriculture Ecosystem and Environment 91: 283-293.

13. Simone RA, Thomas CJ (2007) Carbon cycling in large lakes of the world A synthesis of production, burial, and lake-atmosphere exchange estimates. Global Biogeochemical Cycle 21: GB3002.

14. Yadav RC (2007) Entrap and eradicate the $\mathrm{CO}_{2}$ : A new method for reducing global warming. WSEA conference on environment Athen.

15. Mosier A, Schiemel D, Valentine D, Bonson K, Parton W (1991) Methane and nitrous oxide fluxes in native, fertilized and cultivated grasslands. Nature 350 330-332.

16. Streigi RG, McConnaughey TA, Thorestenson DC, Weeks EP, Woodward JC (1992) Consumption of atmospheric methane by desert soils. Nature 357: 145147.

17. Yadav RC, Om Prakash, Deshwal JS (2012) Intra row banding of cyno-bacteria 
leguminous crops to enhance productivity of cereals and oilseed crops. Abstract accepted for presentation at World Biotechnolgy Congress 2013, June $3-6$, Boston, USA.
18. Yadav RC (2012) Innovative applications for zero methane emission and enhancing productivity of paddy fields for sustainable global food security Agri. Eco System and Environment Netherland Communicated. 